RESEARCH ARTICLE

\title{
Production of Volatile Organic Compounds of Fusarium oxysporum f. sp. lycopersici on Coinoculation with the Metabolites of Chaetomium globosum
}

\author{
Sangeetha C* and Krishnamoorthy A S \\ Department of Plant Pathology, Tamil Nadu Agricultural University, Coimbatore -641003
}

\begin{abstract}
The present study focused on divulging the effect of 15 and 30 days old culture filtrates of Chaetomium globosum on the mycelial growth and toxin production of Fusarium oxysporum f. sp. Iycopersici. The cell-free culture (CFC) filtrate of $\mathrm{C}$. globosum was inoculated in the liquid medium of $\mathrm{F}$. oxysporum $\mathrm{f}$. $\mathrm{sp}$. lycopersici. The results revealed that mycelial growth was reduced in the CFC filtrate of C. globosum inoculated medium compared to control (pathogen alone). The mycelial dry weight of the F. oxysporum f. sp. lycopersici was $0.864 \mathrm{~g}$ in fifteen days old CFC filtrate followed by 30 days old CFC filtrate of C. globosum (1.374g) amended medium. Metabolites from the CFC filtrate and control were extracted separately using chloroform followed by ethyl acetate and the extract was subjected to GC-MS analysis. GC-MS analyses showed that methyl ester group was present in 15 days old culture filtrate condensate compared to 30 days old CFC. The compounds are methyl tetradecanoate, octadecanoic acid, methyl ester, and DL-Proline, 5-oxo-, methyl ester. Thirty days old culture filtrate condensate of $\mathrm{C}$. globosum contained more phenol groups like phenol 2,4-bis (1,1-dimethylethyl) at 17.62 RT followed by diisooctyl phthalate, 17-pentatriacontene, cholestan-3-ol, 2-methylene-, (3a,5a) and bicycle [4.1.0]heptanes,-3-cyclopropyl,-7-hydroxymethyl,trans. Metabolites of F. o. f. sp. lycopersici were also characterized by GC-MS, which showed very few volatile compounds like methyl tetradecanone, oleic acid, eicosyl ester, methyl stearate, and bis(2-ethylhexyl)phthalate. These compounds were not detected in co-inoculation of 15 and 30 days old CFC filtrate of C. globosum and F. o. f. sp. lycopersici. The difference in the volatile profile may be due to the effect of the metabolites of C. globosum on F. o. f.sp. lycopersici.
\end{abstract}

Keywords: Culture filtrate condensate; Chaetomium globosum; Fusarium oxysporum f. sp. lycopersici

\section{INTRODUCTION}

Fusarium causing wilt disease in tomato persists in soil for long period and produces survival structures such as chlamydospores (Goyal et al., 1973 and Shuxian et al.1998). Complete control of Fusarium is very difficult with a conventional method. Even though fungicides are used for the management of many pathogens, continuous use of such chemicals are reported to induce the resurgence of existing pathogens and the emergence of new races, posing a greater threat. At this juncture, biomolecules from the secondary metabolites have multiple advantages to manage plant pathogens and induce plant growth. Microbes producing secondary metabolites are called mycotoxin, present in the growing medium as well as in the plant tissue. Secondary metabolites of several fungi are known to possess an inhibitory effect on plant pathogenic fungi, bacteria and viruses (Janssens et al., 1992; Breheret et al., 1997 and Marumoto et al., 1997). The involvement of secondary metabolites in plant disease and particularly in the interaction between beneficial and pathogenic fungi, has been studied by several scientists (Fravel, 1988). Every microorganism produces different nature of secondary metabolites with low molecular weight compounds. Trichoderma spp is known to produce several secondary metabolites that are toxic for plant pathogenic fungi. Secondary metabolite compounds from Trichoderma spp are pyrone 6-pentyl-2H-pyran2-one; koninginins; viridians; harzianopyridone; azaphilones; butenolides ; hydroxyl -lactones; isocyano metabolites; diketopiperazines; gliotoxin; gliovirin and peptaibols. A pyrone 6-pentyl-2H- 
pyran-2-one is a metabolite purified from the culture filtrate of Trichoderma spp, responsible for coconut aroma and has shown antifungal activity against several plant pathogens (Scarselletti and Faull., 1994; Worasatit et al., 1994). Likewise, Chaetomium spp also produces several biologically active compounds such as chaetoglobosin A, C, $D, E, G, R$, chaetoviridins, chetomin, chaetocin, chaetochromins, cochliodinol, mollicellin, oosporein, ergosterol, allantoin, uracil, and sterigmatocystin (Brewer et al., 1968; Cole and Cox, 1981; Park et al., 2005; Fogle et al., 2007; Aggrawal, 2015). Biswas et al. (2000 and 2012) studied the characterization of antifungal metabolites from C. globosum and their antagonism against fungal plant pathogens. Soytong (1992) and Soytong et al. (2001) showed that a specific isolate of $C$. cupreum produced secondary metabolites that significantly suppressed tomato wilt caused by F. oxysporum f. sp. Iycopersici and later found that this isolate of $C$. cupreum produced rotiorinols $A$ to $C$ and rotiorin, which also exhibited antifungal activity against Candida albicans (Kanokmedhakul et al., 2006 and Phong et al., 2016). C. globosum produces the antibiotic chaetoglobosin C, which suppressed the growth of many plant pathogens such as Colletotrichum gloeosporioides, C. dematium, Fusarium oxysporum, Phytophthora palmivora, P. parasitica, P. cactorum, Pyricularia oryzae, and Sclerotium rolfsii (Soytong et al., 2001). Some compounds have been reported to possess significant biological activities, such as cytotoxic, enzyme inhibitory, and antibiotic (Gunatilaka, 2006; Scherlach et al., 2010). The antimicrobial activity of chaetoglobosin-C, which is produced by $\mathrm{C}$. elatum ChE01, and C. Iucknowense CLT01 could be involved in the disease control mechanism of these antagonistic fungi against tomato wilt fungus F. oxysporum f. sp. lycopersici (Thohinung et al., 2010). With this background, the current study on the reduction of secondary metabolite secretion of $F$. o. f. sp. lycopersici in the culture medium was tested by adding beneficial microbe of $C$. globosum under in vitro conditions.

\section{MATERIAL AND METHODS}

\section{Isolation and identification of C.globosum and F. oxysporum f. sp. lycopersici}

Fusarium sp. was isolated from the infected plant tissue of the tomato. The same field bioagent of Chaetomium spp was also isolated and both pathogens and bioagents were identified based on the morphological and molecular level, and the molecular sequence of C. globosum (MN069626.1) and F. oxysporum f. sp. lycopersici (MN071397.1) were submitted into NCBI.

\section{Collection of cell free culture (CFC) filtrates}

The conical flasks containing sterilized PDA broth were inoculated with mycelial discs of $C$. globosum, measuring $6 \mathrm{~mm}$ diameter ( 5 numbers in each flask). The flasks were placed in an incubator cum shaker maintained at $25^{\circ} \mathrm{C}$ and agitated at 120 rpm. The culture filtrates were collected at 15 and 30 days after inoculation under aseptic conditions, filtered through a membrane filter $(0.2 \mu \mathrm{m})$. The CFC filtrates were used to arrest the mycelial growth and metabolite production of $F$. oxysporum f. sp. lycopersici.

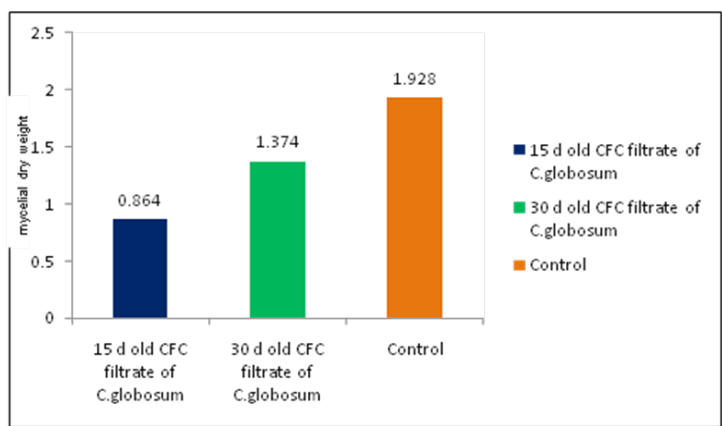

Figure 1. Effect of Cell-Free Culture (CFC) filtrate of C. globosum on mycelia growth of $\mathbf{F}$. oxysporum f. sp. lycopersici

Bioassay of cell-free culture filtrates of C. globosum on inhibition of the mycelial and metabolite production of F. oxysporum f. sp. lycopersici

Cell-free culture filtrates ( 15 and 30 days old) of C. globosum were aseptically mixed with sterilized liquid medium separately in each flask at the rate of $1 \mathrm{~mL}$ in $100 \mathrm{~mL}$ broth. Then, a $5 \mathrm{~mm}$ mycelial disc of the test pathogen was inoculated in the same flask, placed in an incubator, and maintained at $25^{\circ} \mathrm{C}$, and agitated at $120 \mathrm{rpm}$. The ingredients of the liquid medium contained $0.5 \mathrm{~g}$ malt extract; one gram of peptone; one gram of $\mathrm{KH}_{2} \mathrm{PO}_{4}, 0.3 \mathrm{~g}$ $\mathrm{MgSO}_{4} .7 \mathrm{H}_{2} \mathrm{O}$; $0.3 \mathrm{~g} \mathrm{KCL}$; one $\mathrm{mL}$ of $\mathrm{CuSO}_{4} .5 \mathrm{H}_{2} \mathrm{O}$ solution ( $0.005 \mathrm{~g}$ dissolved in one lit.) and one $\mathrm{mL}$ of $\mathrm{ZnSO}_{4} .7 \mathrm{H}_{2} \mathrm{O}$ solution ( $0.01 \mathrm{~g}$ dissolved in one lit) per lit. The pathogen alone in the liquid medium without cell-free culture filtrates served as a control. Three replications were maintained in each treatment. Ten days after incubation, the mycelial mat and the culture filtrates were separated by filtration through Whatman No.40 filter paper. The mycelial dry weight of the pathogen was taken separately in each treatment to know the biomass production.

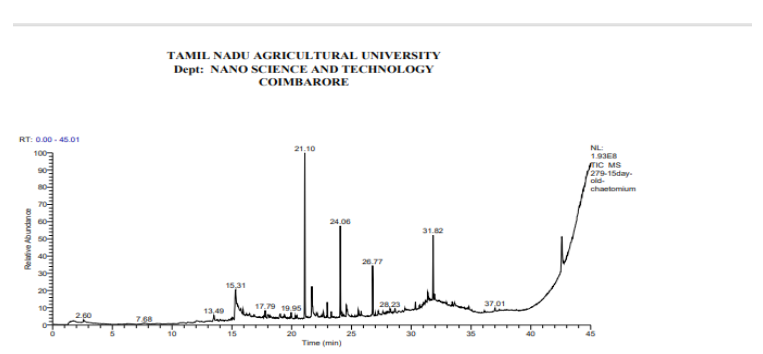

Figure 2. Total ion chromatogram of fifteenday old Cell-Free Culture (CFC) of C. globosum

$107|10-12| 2$ 


\section{Extraction of Toxin}

After separating the mycelial mat, the ten days old cell free culture filtrates of F. o. f. sp. lycopersici were taken, which were grown separately in a liquid medium containing one percent of 15 and 30 days old cell free culture filtrates of $C$. globosum. The pathogen alone was grown in a liquid medium as a control used for toxin extraction. Then the filtrate was further centrifuged at $10,000 \mathrm{rpm}$ for $15 \mathrm{~min}$. The cell-free culture filtrate was extracted with organic solvents like chloroform and ethyl acetate. Liquidliquid extraction was carried out using chloroform, and the compound-containing layer was collected separately. Subsequently, the remaining aqueous layer was mixed equally with ethyl acetate. Then, the compound containing layer was separated. This was repeated three times with an equal volume of solvents. The two organic solvent layers were pooled together and it was evaporated under reduced pressure using a rotary evaporator to obtain the compound residues. The condensate of the solvent layer was dried and dissolved in methanol $(1 \mathrm{mg} / \mathrm{mL})$, filtered through a membrane filter (0.2 $\mu \mathrm{m})$, and stored at $4^{\circ} \mathrm{C}$ for GC-MS analysis. The compounds were also extracted from the 15 and $30^{\text {th }}$ day old culture filtrate of $C$. globosum and liquid medium alone without fungus by using a method as described above. The extracted compounds were further characterized by GC-MS for compound identification.

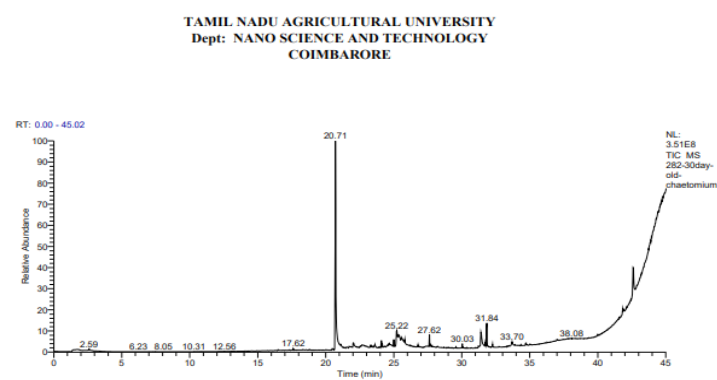

Figure 3. Total ion chromatogram of thirty days old Cell-Free Culture (CFC) of C. globosum

\section{Characterization of toxin through GC-MS}

Characterization of CFC filtrate condensate of F. oxysporum f. sp. lycopersici was done by GC-MS analysis. The column Elite-5MS (100 per cent Dimethyl poly siloxane), $30 \times 0.25 \mathrm{~mm} \times 0.25 \mu \mathrm{m}$ df equipped with GC Clarus 500 Perkin Elmer and turbo mass - gold - Perkin - Elmer detector was used. The carrier gas (helium) flow rate was one $\mathrm{mL}$ per min, split 10:1 and injected volumes were two $\mu \mathrm{L}$. The column temperature was maintained initially at $110^{\circ} \mathrm{C}$ at the rate of $10^{\circ} \mathrm{C} / \mathrm{min}$ followed by increasing up to $280^{\circ} \mathrm{C}$ at the rate of $5^{\circ} \mathrm{C} / \mathrm{min}$ and hold time $9 \mathrm{~min}$. The injector temperature was $250^{\circ} \mathrm{C}$ and this temperature was held constant for
$36 \mathrm{~min}$. The electron impact energy was $70 \mathrm{e} \mathrm{V}$, the Julet line temperature was set at $2000^{\circ} \mathrm{C}$ and the source temperature was set at $200^{\circ} \mathrm{C}$. Electron impact (EI) mass scan $(\mathrm{m} / \mathrm{z}$ ) was recorded in the 45-450 aMU range. Using computer searches on the NIST Ver. 2011 MS data library and comparing the spectrum obtained through GC - MS the compounds present in the sample were identified.

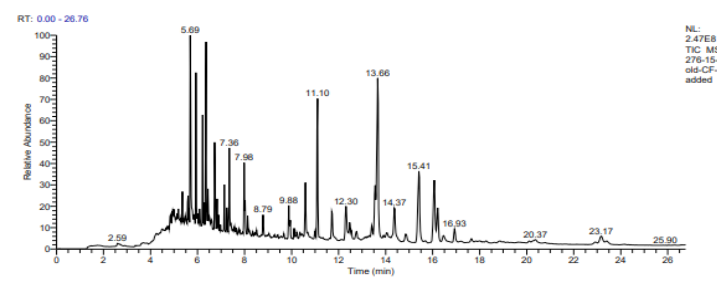

Figure 4. Co inoculation of 15 day old cell-free culture (CFC) filtrate of C. globosum and F.oxysporum f.sp. lycopersici

\section{RESULTS AND DISCUSSION}

Growth of Fusarium oxysporum f. sp. Iycopersici in metabolite amended medium

F. oxysporum f. sp. lycopersici caused wilt disease in tomatoes leading to yield losses reducing production and productivity of tomato (Hussain et al., 2016). The result of the current study is revealed that the fungus, F. oxysporum f. sp. lycopersici was able to grow in fifteen and thirty days old CFC filtrate of $C$. globosum amended medium at one per cent concentration. Nevertheless, the mycelia growth of F. oxysporum f. sp. lycopersici was less in these two treatments when compared with control.

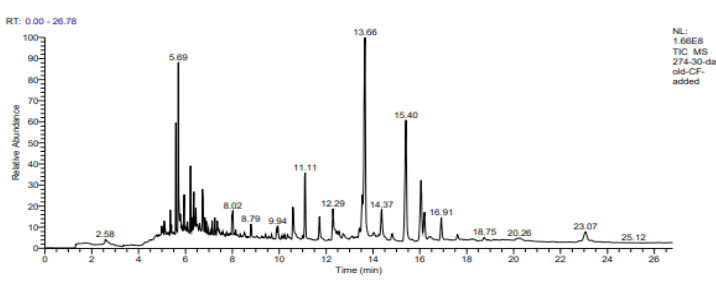

Figure 5. Co inoculation of 30th day old cell free culture (CFC) filtrate of C. globosum and F. oxysporum f. sp. lycopersici

The mycelial dry weight of the F. oxysporum f. sp. lycopersici was recorded only $0.864 \mathrm{~g}$ in fifteen days old CFC filtrate followed by thirty days old CFC filtrate of C. globosum (1.374g) amended medium (Figure 1). Rashmi et al. (2011) reported that antagonistic fungal mycelial growth was suppressed when the other fungus was grown in a toxin amended medium.

Detection of compounds present in the metabolite from the CFC filtrate of

\section{C. globosum (Ch2) through GC-MS}

Culture filtrates of 15 and 30 days - old cultures of C. globosum were subjected to GC-MS analysis. 
The results of GC-MS analysis of ethyl acetate fraction of fifteen days old CFC filtrate condensate of C. globosum (Ch2) was found to have the presence of nine different compounds viz., DLProline, 5-oxo-, methyl ester; Cyclopropanebutanoic acid, 2-[[2-[[2-[(2-pentylcyclopropyl) methyl] cyclopropyl]methyl] cyclopropyl] methyl]-, methyl ester; Hexadecanoic acid, methyl ester; Methyl tetradecanoate; Octadecanoic acid, methyl ester; Docosanoic acid, 1,2,3-propanetriyl ester; Diisooctyl phthalate; Tetradecanoic acid and 1-Monolinoleoylglycerol trimethylsilyl ether (Table1 and Figure 2). Soytong (1992) and Soytong et al. (2001) also reported that an isolate of Chaetomium cupreum producing metabolites significantly suppressed the mycelial growth of F. oxysporum $\mathrm{f}$. sp. lycopersici causing wilt disease of tomato.

Table 1. GC-MS analysis of chloroform and ethyl acetate fraction of $15^{\text {th }}$ days old cell-free culture filtrate condensate of C. globosum (Chg2)

\begin{tabular}{|c|c|c|c|c|c|}
\hline RT & Compound & $\begin{array}{l}\text { Molecular } \\
\text { formula }\end{array}$ & $\begin{array}{l}\text { MW } \\
\text { (g/ } \\
\text { mol) }\end{array}$ & $\begin{array}{l}\text { Peak area } \\
\text { (per cent) }\end{array}$ & Probability \\
\hline 15.31 & DL-Proline, 5-oxo-, methyl ester & $\mathrm{C}_{6} \mathrm{H}_{9} \mathrm{NO}_{3}$ & 143.14 & 13.52 & 42.41 \\
\hline 17.79 & $\begin{array}{l}\text { C y c I o p r o p a n e b u t a n o i c + a c i d , } \\
\text { 2-[[2-[[2-[(2-pentylcyclopropyl)methyl]cyclopropyl]methyl] } \\
\text { c yclopropyl]methyl]-, methyl ester }\end{array}$ & $\mathrm{C}_{25} \mathrm{H}_{34} \mathrm{O}_{2}$ & 374.6 & 0.80 & 8.12 \\
\hline 24.06 & Hexadecanoic acid, methyl ester & $\mathrm{C}_{17} \mathrm{H}_{34} \mathrm{O}_{2}$ & 270.45 & 5.96 & 75.73 \\
\hline 21.10 & Methyl tetradecanoate & $\mathrm{C}_{15} \mathrm{H}_{30} \mathrm{O}_{2}$ & 242.40 & 9.51 & 72.51 \\
\hline 26.77 & Octadecanoic acid, methyl ester & $\mathrm{C}_{19} \mathrm{H}_{38} \mathrm{O}_{2}$ & 298.50 & 3.13 & 51.92 \\
\hline 28.23 & Docosanoic acid, 1,2,3-propanetriyl ester & $\mathrm{C}_{69} \mathrm{H}_{134} \mathrm{O}_{6}$ & 1059.7 & 1.27 & 13.27 \\
\hline 31.82 & Diisooctyl phthalate & $\mathrm{C}_{24} \mathrm{H}_{38} \mathrm{O}_{4}$ & 390.60 & 11.94 & 21.35 \\
\hline 21.71 & Tetradecanoic acid & $\mathrm{C}_{14} \mathrm{H}_{28} \mathrm{O}_{2}$ & 229.36 & 5.58 & 49.07 \\
\hline 37.01 & 1-Monolinoleoylglycerol trimethylsilyl ether & $\mathrm{C}_{27} \mathrm{H}_{54} \mathrm{O}_{4} \mathrm{Si}_{2}$ & 500.9 & 0.51 & 35.71 \\
\hline
\end{tabular}

RT-Retention time, MW - Molecular weight

GC-MS analysis of ethyl acetate fraction of thirty days old CFC filtrate condensate of $C$. globosum (Chg2) indicated the presence of six major volatile compounds. The compounds are namely, hexadecanoic acid, methyl ester; phenol, 2,4-bis(1,1dimethylethyl); bicyclo[4.1.0]heptane,-3-cyclopropyl,7-hydroxymethyl, trans; cholestan-3-ol, 2-methylene; 17-Pentatriacontene and Diisooctyl phthalate (Table 2 and Figure 3). Biswas et al. (2000 and 2012) studied the identification and characterization of antifungal compounds like chaetoglobosin and chaetomin produced by C. globosum. These two compounds significantly suppressed the redial growth of the plant pathogens such as Bipolaris sorokiniana, Macrophomina phaseolina, Rhizoctonia solani and Phytium ultimum. They also reported that chaetoglobosin at the rate of $1000 \mathrm{ppm}$ and 500ppm mixed medium showed only $13 \mathrm{~mm}$ and $17 \mathrm{~mm}$ mycelial growth of Bipolaris sorokiniana compared with control (69mm).

Table 2. GC-MS analysis of chloroform and ethyl acetate fraction of $30^{\text {th }}$ days old culture filtrate condensate of $C$. globosum (Chg2)

\begin{tabular}{llllll}
\hline RT & \multicolumn{1}{c}{ Compound } & $\begin{array}{c}\text { Molecular } \\
\text { formula }\end{array}$ & $\begin{array}{c}\text { MW } \\
\mathbf{( g / m o l} \text { ) }\end{array}$ & $\begin{array}{c}\text { Peak area } \\
\text { (per cent) }\end{array}$ & Probability \\
\hline 24.06 & Hexadecanoic acid, methyl ester & $\mathrm{C}_{17} \mathrm{H}_{34} \mathrm{O}_{2}$ & 270.45 & 2.53 & 75.73 \\
17.62 & Phenol, 2,4-bis(1,1-dimethylethyl) & $\mathrm{C}_{17} \mathrm{H}_{30} \mathrm{OSi}$ & 278.5 & 0.63 & 46.18 \\
20.71 & Bicyclo[4.1.0]heptane,-3-cyclopropyl,-7-hydroxymethyl, trans & $\mathrm{C}_{11} \mathrm{H}_{18} \mathrm{O}$ & 166.26 & 31.51 & 5.07 \\
22.04 & Cholestan-3-ol, 2-methylene-, (3á,5à) & $\mathrm{C}_{27} \mathrm{H}_{48} \mathrm{O}$ & 388.7 & 13.89 & 8.48 \\
30.03 & 17-Pentatriacontene & $\mathrm{C}_{35} \mathrm{H}_{70}$ & 490.9 & 0.47 & 21.78 \\
31.84 & Diisooctyl phthalate & $\mathrm{C}_{24} \mathrm{H}_{38} \mathrm{O}_{4}$ & 390.60 & 3.46 & 23.20
\end{tabular}


Identification of volatile compounds from $F$. oxysporum f. sp. lycopersici (alone) and CFC filtrate of C.globosum amended medium

The volatile compound emission was higher in fifteen days old CFC filtrate when compared to thirty days old CFC filtrate. Among these two, two similar compounds were observed namely hexadecanoic acid, methyl ester, and diisooctyl phthalate. Hexadecanoic acid and methyl ester are having high relative content and probability. Earlier, Praveen Kumar et al. (2010) elucidated that, hexadeconic acid (deconic acid derivatives) possess nematicidal and pesticidal properties.

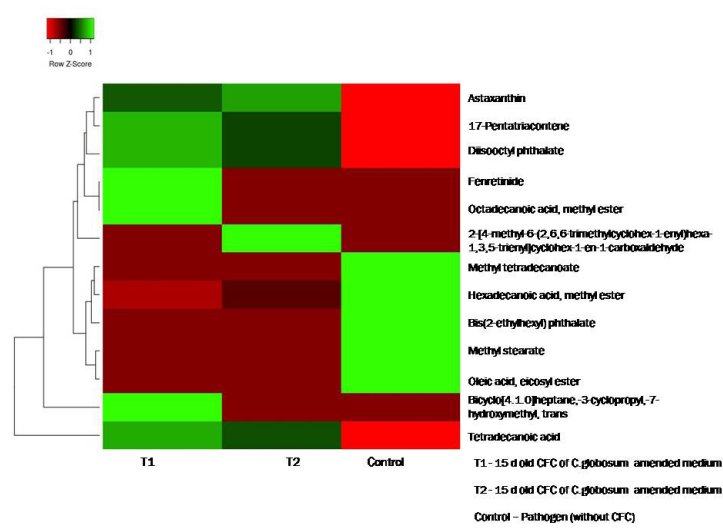

Figure 7. Heat map for Fusarium producing volatile organic compound at different conditions

This compound also had antioxidant and hypocholesterolemic potential. In addition, the authors also illustrated the presence of antiandrogenic flavor compounds, haemolytic and 5-alpha reductase inhibitors in deconic acid derivatives. Volatile metabolites produced by fungi and bacteria have been extensively profiled and reviewed by many scientists (Kai et al., 2009; Kwon et al., 2010 and Sangeetha et al., 2018). Soil microbes even bacteria, fungi, yeast, and other beneficial and pathogenic organisms produce volatile organic compounds that have been described to promote plant growth, induce systemic resistance and inhibit bacterial and fungal growth (Ryu et al.,2003; Fernando et al.,2005; Farag et al.,2006; Schulz et al.,2010; Yuan et al., 2017 and Sangeetha et al., 2018). F. oxysporum f. sp. lycopersici producing volatile organic compounds under normal medium are hexadecanoic acid, methyl ester; methyl tetradecanoate; oleic acid, eicosyl ester; methyl stearate, and bis(2-ethylhexyl) phthalate. Similarly, volatile organic compounds present under fifteen days old cell-free culture filtrate amended medium are octadecanoic acid, methyl ester; bicyclo[4.1.0] heptane, -3-cyclopropyl, -7-hydroxymethyl, trans; 17-Pentatriacontene; disooctyl phthalate; tetradecanoic acid; fenretinide and astaxanthin (Table 3 and Figure 4). Additionally, two compounds were detected namely, hexadecanoic acid, methyl ester; 2-[4-methyl-6-(2,6,6-trimethylcyclohex-1-enyl) hexa-1,3,5-trienyl]cyclohex-1-en-1-carboxaldehyde. However, the three compounds were not found (octadecanoic acid, methyl ester; bicyclo[4.1.0] heptane, -3-cyclopropyl, -7-hydroxymethyl, trans; fenretinide) in thirty days old culture filtrate amended medium (Table 3 and Figure 5). Pathogen under normal medium was compared with CFC filtrate of C. globosum amended medium (treatment). Four

Table 3. Fusarium volatile pattern studied through GC-MS

\begin{tabular}{|c|c|c|c|c|}
\hline RT & Name of the Compounds & $\begin{array}{l}\text { Peak area of pathogen } \\
\text { grown on } 15^{\text {th }} \mathrm{d} \text { old } \\
\text { CFC filtrate of C. } \\
\text { globosum (per cent) }\end{array}$ & $\begin{array}{l}\text { Peak area of pathogen } \\
\text { grown on } 30^{\text {th }} d \text { old CFC } \\
\text { filtrate of C. globosum } \\
\text { (per cent) }\end{array}$ & $\begin{array}{c}\text { Peak area of } \\
\text { pathogen (without } \\
\text { metabolite) (per cent) }\end{array}$ \\
\hline 24.06 & Hexadecanoic acid, methyl ester & - & 0.68 & 3.38 \\
\hline 21.1 & Methyl tetradecanoate & - & - & 4.16 \\
\hline 26.77 & Octadecanoic acid, methyl ester & 3.6 & - & - \\
\hline 20.71 & $\begin{array}{l}\text { Bicyclo[4.1.0]heptane,-3-cyclopropyl,-7- } \\
\text { hydroxymethyl, trans }\end{array}$ & 12.52 & - & - \\
\hline 30.03 & 17-Pentatriacontene & 2.68 & 1.92 & - \\
\hline 31.84 & Diisooctyl phthalate & 4.94 & 3.55 & - \\
\hline 5.69 & Tetradecanoic acid & 15.31 & 12.11 & - \\
\hline \multirow[t]{2}{*}{12.30} & Fenretinide & 3.67 & - & - \\
\hline & Oleic acid, eicosyl ester & - & - & 1.17 \\
\hline 12.29 & $\begin{array}{l}\text { 2-[4-methyl-6-(2,6,6-trimethylcyclohex- } \\
\text { 1-enyl)hexa-1,3,5-trienyl]cyclohex-1-en- } \\
\text { 1-carboxaldehyde }\end{array}$ & - & 4.15 & - \\
\hline 14.37 & Astaxanthin & 2.46 & 3.00 & - \\
\hline 26.77 & Methyl stearate & - & - & 1.94 \\
\hline 31.84 & Bis(2-ethylhexyl) phthalate & - & - & 5.32 \\
\hline
\end{tabular}


compounds were produced by $F$. oxysporum f. sp. lycopersici, namely, methyl tetradecanoate; oleic acid, eicosyl ester; methyl stearate, and bis(2ethylhexyl) phthalate (Table 3 and Figure 6). Cluster heat map analysis expressed the area percentage of compounds in the column and the treatment details represent in the row (Figure 7 ). These compounds are having antifungal and anti-bacterial activity (Rowsh anul Habib and Rezaul Karim, 2009; Abubakar and Majinda, 2016). F. oxysporum f. sp. lycopersici also produces antimicrobial compounds for their survivability in toxin amended medium.

\section{CONCLUSION}

The current investigation revealed the reduction of mycelial growth and toxin production of $F$. oxysporum f. sp. lycopersici under different days old cell-free culture (CFC) filtrate of Chaetomium globosum amended medium. The mycelial dry weight of $F$. oxysporum f. sp. lycopersici was recorded to be only fifty per cent in fifteen days old cell-free culture filtrate amended medium. The volatile organic compounds were characterized through GC-MS. Fatty acid, phenol, and terpenoids compounds were present in cell-free culture filtrate of $C$. globosum and this might be responsible for the reduction of mycelial dry weight. However, the additional compounds from the culture filtrate of F. oxysporum f. sp. lycopersici have antimicrobial nature for their self-survivability. Further study is needed to test compound compatibility and explore a mode of action against plant pathogens.

\section{FUNDING AND ACKNOWLEDGMENT}

The authors thank the Department of Science and Technology, Government of India for financial support vide reference no SR/WOS-A/LS-284/2017 under the Women Scientist Scheme to complete this work. The authors also acknowledge the Department of Plant Pathology, Centre for Plant Protection Studies, Tamil Nadu Agricultural University, Coimbatore, for giving the laboratory support to carry out this experiment.

\section{REFERENCES}

Aggarwal, R. 2015. Chaetomium globosum: A potential biocontrol agent and its mechanism of action. Indian Phytopathol., 68(1): 8-24.

Biswas, S.K., Aggarwal, R., Srivastava, K.D., Gupta, S. and P. Dureja. 2012. Characterization of antifungal metabolites of Chaetomium globosum Kunze and their antagonism against fungal plant pathogens. Journal of Biol. Control., 26 (1): 70-74.

Biswas, S.K., Srivastava, K.D., Aggarwal, R., Dureja, P. and D.V. Singh. 2000. Antagonism of Chaetomium globosum to Drechslera sorokininana, the spot blotch pathogen of wheat. Indian Phtytopathol., 53:436-440.
Brewer, D., Jerram, W.A. and Taylor. A. 1968. The production of cochilodinol and a related metabolite Chaetomium species. Can. J. Microbiol., 14:861866.

Cole, R. and R.H. Cox, 1981. Handbook of toxic fungal metabolites: the cytochalasins. Academic press, New York. pp. 264-343.

Fogle, M.R., Douglas, D.R., Jumper, C.A. and D.C. Straus 2007. Growth and mycotoxin production by Chaetomium globosum. Mycopathologia., 164:49-56.

Fravel, D. R. 1988. Role of antibiosis in the biocontrol of plant diseases. Annu Rev Phytopathol., 26: 75-91.

Goyal, J.P., Maraite, H. and J. A. Meyer. 1973. Abundant production of chlamydospores by Fusarium oxysporum f. sp. melonis in soil extract with glucose. Neth. J. PI. Path., 79: 162 -164.

Gunatilaka, A. A. L. 2006. Natural products from plantassociated microorganisms: distribution, structural diversity, bioactivity, and implications of their occurrence. J. Nat. Prod., 69:509-526.

Hussain, I., Alam, S.S., Khan I., Shah, B., Naeem, A., Khan, N. and S. R. A. Shah. 2016. Study on the biological control of Fusarium wilt of tomato. $J$ Entomol Zool Stud., 4:525-528.

Kanokmedhakul, S., Kanokmedhakul, K., Nasomjai, P., Loungsysouphanh, S., Soytong, K., Sobe, M., Kongsaeree, K., Prabpai, S. and A. Suksamran. 2006. Antifungal Azaphilones from the fungus, Chaetomium cupreum CC3003. J. Nat.Prod., 69:891-895

Kwon, Y.S., Ryu, C.M., Lee, S., Park, H.B., Han, K.S., Lee, J.H., Lee, K., Chung, W.S., Jeong, M. J. and H. K. Kim. 2010. Proteome analysis of Arabidopsis seedlings exposed to bacterial volatiles. Planta., 232: 1355-1370.

Mustapha, N., Abubakar and R. R. T. Majinda 2016. GC - MS analysis and preliminary antimicrobial activity of Albizia adianthifolia (Schumach) and Pterocarpus angolensis (DC). Medicines., 3(3):1-9.

Park, J. H., Choi, G. J., Jang, K. S., Lim, H. K., Kim, H. T., Cho, K.Y. and J.C. Kim. 2005. Antifungal activity against plant pathogenic fungi of chaetoviridins isolated from Chaetomium globosum. FEMS Microbiol. Lett., 252: 309- 313.

Phong, N., Huu, W., Pongnak and K. Soytong. 2016. Antifungal activities of Chaetomium spp. against Fusarium wilt of tea. Plant Prot. Sci., 52:10-17.

Rowsh anul Habib, M. and M. Rezaul Karim. 2009. Antimicrobial and cytotoxic activity of di-(2ethylhexyl) phthalate and anhydrosophoradiol-3actate isolated from Calotropis gigantean (Linn.) flower. Mycobiology., 37 (1): 31-36.

Sangeetha C., Krishnamoorthy, A.S., Kiran Kumar N.and I. Arumuka Pravin. 2018. Effect of Headspace and trapped volatile organic compounds (VOCs) of the Chinese caterpillar mushroom, Ophiocordyceps sinensis (Ascomycetes) against soil borne plant pathogens. Int. J. Med. Mushrooms., 20(9):825835. 
Scarselletti, R. and J. L.Faull. 1994. In vitro activity of 6-pentyl-a-pyrone, a metabolite of Trichoderma harzianum, in the inhibition of Rhizoctonia solani and Fusarium oxysporum f. sp. lycopersici. Mycol Res., 98: 1207-09.

Scherlach, K., Boettger, D., Remme, N. and C. Hertweck. 2010. The chemistry and biology of cytochalasans. Nat. Prod. Rep., 27:869-886.

Shuxian, L., Hartman, G. L. and L. E.Gray. 1998. Chlamydospore formation, production, and nuclear status in Fusarium solani f. sp. glycines soybean sudden death syndrome causing isolates. Mycologia., 90 (3): 414-421.

Soytong, K. 1992. Biological control of tomato wilt caused by Fusarium oxysporum f. sp. lycopersici using Chaetomium cupreum. Kasetsart J. (Nat. Sci.)., 26:310-313.
Soytong, K., Kanokmedhakul, S., Kukongviriyapa, V. and M. Isobe. 2001. Application of Chaetomium species (Ketomium ${ }^{\circledR}$ ) as a new broad spectrum biological fungicide for plant disease control: A review article. Fungal Divers., 7:1-15.

Thohinung, S., Kanokmedhakul, S., Kanokmedhakul, K., Kukongviriyapan, V., Tusskorn, O. and K. Soytong. 2010. Cytotoxic 10-(indol-3-yl)-[13] cytochalasans from the fungus Chaetomium elatum ChE01. Archives of Pharmaceutical Research., 33:11351141.

Worasatit, N., Sivasithamparam, K., Ghisalberti, E. L. and C. Rowland. 1994. Variation in pyrone production, pectic enzymes and control of rhizoctonia root rot of wheat among single-spore isolates of Trichoderma koningii. Mycol Res., 98: 1357-1363. 